Etnográfica

Revista do Centro em Rede de Investigação em

Antropologia

vol. $16(1) \mid 2012$

Vol. $16(1)$

\title{
D. Ann Herring e Alan C. Swedlund (orgs.), Plagues and Epidemics: Infected Spaces, Past and Present
}

\section{Mónica Saavedra}

\section{OpenEdition}

\section{Journals}

Edição electrónica

URL: https://journals.openedition.org/etnografica/1444

DOI: 10.4000/etnografica. 1444

ISSN: 2182-2891

\section{Editora}

Centro em Rede de Investigação em Antropologia

\section{Edição impressa}

Data de publição: 1 fevereiro 2012

Paginação: 205-208

ISSN: 0873-6561

\section{Refêrencia eletrónica}

Mónica Saavedra, «D. Ann Herring e Alan C. Swedlund (orgs.), Plaques and Epidemics: Infected Spaces, Past and Present», Etnográfica [Online], vol. 16 (1) | 2012, posto online no dia 06 março 2012, consultado o 12 fevereiro 2022. URL: http://journals.openedition.org/etnografica/1444 ; DOI: https:// doi.org/10.4000/etnografica.1444

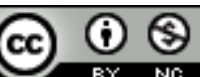

Etnográfica is licensed under a Creative Commons Attribution-NonCommercial 4.0 International License. 
Ressalta uma grande variedade, sem hipótese de homogeneização.

Através de dados sobre alguns dos jogadores de futebol mais internacionais, segue-se a análise de uma interessante analogia entre cidades globais e "clubes globais" em "Porque todos os 'rebeldes' falam português?...", de Carmen Rial. A autora resgata Freyre para refletir sobre a imagem idealizada destes jogadores da América do Sul, e destaca que a Europa apresenta uma diversidade de construções retóricas de raça e origem étnica, retomando a necessidade de refletir sobre as configurações destes discursos, trazendo a mobilidade para a equação. As viagens destes jogadores realçam a mobilidade social - a viagem como deslocação geográfica e na hierarquia social (com Lévi-Strauss).

José Mapril, em “'Os novos VIP’: políticas de mobilidade, emigração e nação no Bangladesh contemporâneo", detém-se num assunto pouco abordado na área das migrações - é que às vezes são os Estados que promovem a emigração. Mapril foi atrás dessa história no Bangladesh, seguindo os discursos políticos e institucionais para analisar o contexto em causa. $\mathrm{O}$ objetivo é acrescentar a emigração às demais preocupações da governamentalidade, uma vez que, como neste caso, foi mesmo institucionalizada uma indústria de exportação de mão de obra, que acaba por ser o garante da desejada "modernidade" no Bangladesh e que faz destes emigrantes os novos VIP.

O último capítulo equaciona a mobilidade através da análise da fundação de uma Igreja. "Circunscrição moral: mobilidade, diáspora e configurações doutrinais na Igreja Tokoísta (Angola)", de Ruy Blanes, leva-nos a conhecer o processo de crescimento da Igreja em causa. Este é um processo que depende da mobilidade dos seus principais representantes. Religião e migrações são aqui cruzadas com a ajuda das políticas estatais. Sem falar de poder nem de controlo, é a mobilidade no seu estatuto conceptual contemporâneo que permite cruzar dinâmicas culturais distintas.

Nesta coletânea, quando a mobilidade aparece como parte do método de pesquisa, os artigos resultam mais seguros; quando a mobilidade surge como possibilidade interpretativa, provocam uma sensação de insegurança analítica. É possível que esta situação ocorra justamente porque a mobilidade atravessa uma recomposição conceptual e porque a sua história é dificilmente abarcável seguindo apenas uma disciplina de cada vez. A mobilidade e suas dimensões, como exemplifica bem este livro, requer interdisciplinaridade.

\section{Rita d'Ávila Cachado}

CIES-IUL, Portugal

ritacachado@gmail.com
D. Ann Herring

e Alan C. Swedlund (orgs.)

PLAGUES AND EPIDEMICS:

INFECTED SPACES, PAST

AND PRESENT

Oxford e Nova Iorque, Berg, 2010 ,

417 páginas,

ISBN: 978-184-788-547-0.
Epidemias e pestes são o fio condutor das reflexões que compõem este trabalho coletivo, resultado do encontro realizado em Tucson, Arizona (EUA), em setembro de 2007, entre antropólogos e outros investigadores que trabalham sobre questões sociais da saúde. Trata-se de um conjunto de artigos sobre doenças tão diferentes como a gripe 
de 1918, a gripe aviária, o kuru (um tipo de encefalopatia), o VIH-SIDA, a febre-amarela, a malária, o dengue, e em lugares tão diversos como o Brasil, os EUA, Gibraltar, o México, a Papua Nova Guiné, a Nova Zelândia, o Vietname, etc. Este conjunto de materiais problematiza a articulação entre as escalas internacional, nacional e local na abordagem às epidemias, revelando a fragmentação e desigualdade subjacentes à "globalização da ecologia das doenças". Não apresenta, no entanto, casos do continente africano, terreno de vários trabalhos das ciências sociais sobre medicina e saúde, nomeadamente sobre VIH-SIDA, alguns com uma abordagem transdisciplinar. Esta ausência é, de resto, reconhecida no capítulo introdutório; contudo, é explicada pela intenção de reunir em Tucson propostas inovadoras de abordagem às epidemias e não trabalhos específicos representativos de doenças ou áreas geográficas. Interrogamo-nos se não existem trabalhos inovadores sobre o contexto africano...

Epidemias e doenças infeciosas surgem como uma temática candente para as "angústias epidemiológicas" do século XXI, ante a publicitação de infeções emergentes e reemergentes, bactérias resistentes, vírus lentos, pandemias iminentes. Este livro pretende tornar visíveis os desafios que se colocam à abordagem antropológica num ambiente de ameaças globais, contribuindo para o debate da relação da antropologia com a epidemiologia e a saúde pública, no contexto das políticas internacionais de saúde. Enfatiza ainda a pertinência de uma perspetiva abrangente sobre as epidemias, sugerindo a importância da antropologia no afinamento de estratégias de intervenção em saúde pública que integrem as ações desenvolvidas pelas comunidades, a partir das suas perceções e conceções sobre as doenças.

A diversidade de casos históricos e etnográficos sustenta a intenção manifesta desta coletânea de constituir uma contracorrente à "balcanização do pensamento académico e às divisões na antropologia" (p. 2). Sem terem sido produzidos em articulação uns com os outros ou em diálogo comparativo conjunto, constituem um todo coerente, mostrando as possibilidades de convergência de abordagens e metodologias diversas.

Esta colectânea defende a cooperação entre os diversos ramos da antropologia e constitui um exemplo da sua importância para uma "perspetiva alargada da humanidade" (p. 2), num mundo de especializações que, por vezes, não dão conta da multiplicidade e da diversidade. Mostra ainda a possibilidade de a antropologia se reinventar, repensando instrumentos analíticos e metodologias de acordo com os desafios que se lhe colocam no terreno e apresentando-se com um potencial de intervenção, nomeadamente através do trabalho etnográfico.

Este trabalho conjunto reflete sobre a complexidade das epidemias e das pestes, enfatizando a multiplicidade de significados (com os seus ecos do passado e dinâmicas históricas) que lhes são atribuídos pelos atores envolvidos, nomeadamente aqueles que decorrem de experiências pessoais e localizadas dos indivíduos e das comunidades. Transversal ao conjunto dos trabalhos é também a crítica à tendência para abordar as epidemias como acontecimentos únicos e demarcados no espaço e no tempo; uma espécie de "acidentes epidemiológicos". Realçam, em alternativa, a importância de compreendê-las como fenómenos múltiplos e confluentes, com repercussões no futuro dos indivíduos e das comunidades que afetam. $\mathrm{O}$ enquadramento e a contextualização das doenças enquanto fenómenos social, política, económica e historicamente determinados são noções chave neste livro. Esta perspetiva surge quase como uma epistemologia, na medida em que condiciona as questões colocadas na abordagem aos problemas da saúde e o que se considera 
relevante para a compreensão das questões epidemiológicas.

Nesta lógica de diversidade e multiplicidade, realça-se a importância da diversificação de metodologias na abordagem às epidemias, articulando métodos quantitativos e qualitativos. As epidemias não são redutíveis aos números das estatísticas. Compreendem escolhas pessoais, comportamentos individuais inscritos em redes sociais intrincadas, contextos históricos, culturais, económicos, políticos; mas também emoções, cruzando-se e confundindo-se com os "ciclos de vergonha e culpa, discursos estigmatizantes, isolamento dos doentes, medo do contágio e cenários de fim do mundo" (p. 4) associados às "pestes".

Num contexto de diversidade e desigualdade, compreendido na convergência epidemiológica global, Plagues and Epidemics coloca(-nos) diversas interrogações: quem define as epidemias e com que critérios? Como são descartadas outras explicações e como interagem modelos explicativos diversos? Quais os processos subjacentes ao estabelecimento de explicações consensuais? Nestas explicações carregadas de significados, como se cruzam instituições e organismos governamentais, globais e locais com o quotidiano dos indivíduos?

Referindo-se à problemática dos processos da definição das epidemias, bem como às experiências pessoais e comunitárias das doenças e seus condicionalismos, este livro apresenta-se como um contributo para o desenvolvimento de teorização e análise sobre a problemática das doenças infeciosas emergentes, na antropologia. Como fica dito na introdução, identifica-se, em certa medida, com as propostas da antropologia das doenças infeciosas introduzida por Marcia Inhorn e Peter Brown, no início da década de 90 do século XX, empenhada numa abordagem holista que aproveitasse os enquadramentos teóricos da antropologia em geral. Mas oferece, igualmente, vias de diálogo e comparação com trabalhos da epidemiologia e da antropologia médica anglófonas, que desenvolvem uma perspetiva crítica à epidemiologia, alguns dos quais são referidos ao longo deste livro. Contudo, este diálogo não é explicitado, deixando também de fora as propostas analíticas da epidemiologia crítica e da medicina social, avançadas por investigadores da América Latina (a contribuição de Arachu Castro, Yasmin Khawja e James Johnston, neste livro, é um exemplo concreto desta afinidade), o que levanta questões sobre os limites da "desbalcanização" proposta neste livro, ditados, entre outros fatores, pela reduzida visibilidade dos trabalhos produzidos em línguas que não o inglês, mas também sobre as tendências dominantes dentro da antropologia e o que as determina, bem como sobre divergências teóricas, potencialmente suscitadas pela epidemiologia crítica, de inspiração marxista.

A complexificação das noções de epidemia e peste encontra enquadramento conceptual nas noções de sindemia (syndemic) e ecossindemia (ecosyndemic), presentes ao longo deste livro. Trata-se de conceitos forjados na antropologia médica por Merrill Singer, cuja contribuição nesta coletânea passa por uma síntese sobre as potencialidades da sua operacionalização, referindo a sua difusão para a epidemiologia e a saúde pública (palavras de Singer, p. 25). O conceito de sindemia é, de resto, reconhecido pela epidemiologia (veja-se, por exemplo, o trabalho de Francisco Inácio Bastos, de 2006, AIDS na Terceira Década, publicado pela Fiocruz) como a súmula das sinergias entre fatores sociais, políticos, económicos, ambientais e ação humana, determinantes para a saúde das populações.

$\mathrm{O}$ enquadramento na antropologia médica, bem como a ênfase dada nesta coletânea às desigualdades sociais, à dimensão política e às experiências individuais e coletivas das epidemias justificaria uma 
articulação - ainda que crítica ou alternativa e apresentando-se como "um passo em frente" - com os conceitos de "violência estrutural" e de "sofrimento social" desenvolvidos por Paul Farmer (cujos trabalhos são mencionados neste livro), Veena Das, Arthur Kleinman e outros. Estes conceitos remetem não só para o peso das desigualdades sociais e das relações de poder na saúde dos indivíduos e das comunidades, mas também para os mecanismos de desigualdade e opressão consolidados ao longo de processos históricos seculares e incorporados no quotidiano daqueles que vivem em contextos de pobreza e privação, influenciando a distribuição das doenças infeciosas, bem como as respostas institucionais, comunitárias e pessoais a estas.

Plagues and Epidemics é uma coletânea coerente e aliciante, com momentos empolgantes de etnografia, que dão corpo e emoções às epidemias de hoje e de ontem, mostrando a variação caleidoscópica que compõe a nossa condição de humanos, num mundo dominado por metáforas de risco e ameaças.

\section{Mónica Saavedra \\ CRIA-IUL, Portugal \\ maamsaa@gmail.com}

Roberto Beneduce

ARCHEOLOGIE DEL TRAUMA: UN'ANTROPOLOGIA DEL SOTTOSUOLO

Roma-Bari, Laterza Edizioni, 2010, 218 páginas, ISBN: 978-88-420-9249-0.

\section{CORPI E SAPERI INDOCILI:}

GUARIGIONE, STREGONERIA E POTERE IN CAMERUN

Torino, Bollati Boringhieri, 2010 , 407 páginas, ISBN: 978-88-339-2050-4.

Para conseguir pôr em diálogo as duas recém-publicadas monografias de Roberto Beneduce, é necessário considerar o percurso académico do autor. Psiquiatra e psicoterapeuta de formação, Beneduce começou em 1988 a desenvolver pesquisa no Mali sobre os sistemas terapêuticos locais, trabalhando ao lado de curandeiros como investigador e aprendiz. O diálogo constante entre saberes diferentes, o da biomedicina, de um lado, e do outro as práticas de cura que Beneduce ia frequentando, antes no Mali e depois nos Camarões, torna-se o elemento de distinção do centro de apoio psicológico para imigrantes e refugiados que ele funda em Turim em 1996, o Centro Frantz Fanon. Continua ao mesmo tempo o trabalho clínico e a investigação, indagando a relação complexa entre sofrimento, memória, violência, práticas terapêuticas e retóricas humanitárias.

Editadas ambas em 2010, as publicações que decidi apresentar nesta recensão espelham as duas almas de Beneduce. No primeiro dos dois livros, Archeologie del Trauma, fala mais o terapeuta, as suas dúvidas e inquietações face a dores, feridas e memórias impossíveis de reduzir ao perímetro estreito de um único conceito: o de trauma. Roberto Beneduce interroga aqui modelos e categorias que, no seio de retóricas humanitárias e do saber psiquiátrico, ignoram muitas vezes as diferenças, as responsabilidades, as dimensões político-económicas 